\section{GOBLET: achievements and goals a year on}

\section{GOBLET Consortium}

GOBLET Stichting, CMBI Radboud University, Nijmegen Medical Centre, Nijmegen, The Netherlands

Received 22 January 2014; Published 5 March 2014

Goblet Consortium (2014) EMBnet.journal 20, e751. ṇtțp:!/!. dx.doị.org/10.14806/ej.20.0.751.

The idea to create a Global Organisation for Bioinformatics Learning, Education and Training (GOBLET) was formulated during a satellite meeting' of the $24^{\text {th }}$ Annual General Meeting (AGM) of EMBnet (the Global Bioinformatics Network) in Uppsala, in June 2012. Here, leaders and representatives of ten international societies, networks and institutes concluded that tangible benefits could be realised if organisations whose core business activities involve bioinformatics education and training could more readily share their experiences, expertise and resources. $\mathrm{GOBLET}^{2}$ was subsequently established as a Dutch Foundation, and held its first meeting in Amsterdam in November 2012, hosted by The Netherlands Bioinformatics Centre (NBIC) (GOBLET Consortium, 2013). A year on, we report the outcomes of GOBLET's first AGM: we review its principal achievements, and reflect on future priorities, moving forward.

\section{Annual General Meeting, 2013}

The GOBLET AGM ${ }^{3}$ (GOBLET Consortium, 2013), held at The Genome Analysis Centre (TGAC), Norwich, in November 2013, was attended (or represented) by all 22 eligible organisational members; one individual member also participated. Representatives from the European Bioinformatics Institute, the Wellcome Trust and the Fondazione Edmund Mach observed the meeting. The main goals were l) to report achievements since the kick-off meeting in Amsterdam; II) to announce the results of the first elections; III) to define GOBLET's immediate priorities; and IV) to discuss how the organisation should begin reaching out to the rest of the world.

\footnotetext{
1 www.mygoblet.org/about-us/goblet-events/inauguralb3cb-meeting

2 www.mygoblet.org/

3 www.mygoblet.org/about-us/goblet-events/tgacgobletmeeting
}

Executive and Task-Force Reports

During GOBLET's first year, 14 Gold, eight Silver and two Bronze organisational members were welcomed, together with three individual members. Since the AGM, more individuals have joined, and several further organisations have pledged membership (joining has been facilitated by the recent implementation of a PayPal module for payment of fees online). To afford greater flexibility during lean funding periods, GOBLET uses a mixed financial model, including subscription fees, donations, grants, etc. Therefore, to supplement income from membership fees, a 'networking' grant was also applied for from the Canadian Institutes of Health Research (CIHR) this was eventually successful, providing funds to support a future GOBLET workshop in Toronto.

This has been a very busy year, not just in terms of the recruitment of new members (membership has more than doubled since the original meeting in Uppsala) and the first successful grant application, but also in terms of the number of meetings held and attended by GOBLET members: e.g., the first ELIXIR-UK/GOBLET workshop hosted at TGAC, March 2013; the NextGenBug meeting at the Roslin Institute, June 2013; the interim GOBLET meeting hosted by the ISCB in Berlin, July 2013; the workshop for e-infrastructure trainers at the Hartree Centre, August 2013; the pan-european bioinformatics training strategy workshop at TGAC, November 2013; and so on. Moreover, in addition to these and the forthcoming Toronto workshop, plans are also in hand to organise a GOBLET workshop alongside the Society for Experimental Biology (SEB)'s 2014 AGM, in Manchester in June.

During the year, two other tangible achievements stand out. First, members of GOBLET worked with the ISCB to create, for the first time, a new track for education posters in the annual ISMB conference - the idea was to provide a forum for exploring different models of and/or vehicles for learning and education in bioinformatics (tutorials, workshops, courses, e-learning, and so on), and how these can be used to enhance the understanding and use of bioinformatics across disparate audiences. GOBLET subsequently had its first poster accepted for ISMB 2013 (Figure 1). Second, GOBLET's training portal ${ }^{4}$ was released shortly before the AGM. This is now gaining momentum, and the numbers of uploaded materi-

4 www.mygoblet.org/training-portal 
als and courses are expanding (it is planned to describe the portal more fully in an article to be published later this year).

\section{Election Results}

Following a procedure discussed and agreed during the Berlin meeting, a candidate nomination and election process was conducted online during September and October 2013. The aim was to elect members to the first formal Executive Board, and to the Chair/co-Chair positions of each of the new Committees: I) Learning, Education and Training (LET); II) Outreach and PR; III) Standardisation; IV) Fund-Raising; and V) Technical. The newly elected members (summarised in Table 1) will form GOBLET's first Operational Board, which will henceforth assume responsibility for running the daily business of the Foundation and coordinating its diverse activities. 'state of the field' manuscript from the results. To further support these activities, the Outreach and PR Committee will begin to prepare appropriate materials (brochures, a newsletter, promotional slides, and so on), and will broadcast GOBLET's work using appropriate social media. Acquiring sufficient funds (through grants, subscriptions, sponsorship, etc.) will be essential to support this work and to allow GOBLET to achieve its mission - inevitably, this will be the focus of the FundRaising Committee.

The outcomes of the break-out sessions also highlighted the need for GOBLET to clearly define its training focus. One concrete suggestion was that the LET Committee should oversee the development of a resource kit for educating the self-taught, to better help GOBLET members to train in their communities.

Table 1. Newly elected members forming GOBLET's first Operational Board.

\begin{tabular}{|c|c|}
\hline \multicolumn{2}{|c|}{ GOBLET OPERATIONAL BOARD } \\
\hline Executive Board & Outreach \& PR Committee \\
\hline Chair: Terri Attwood & Chair: Erik Bongcam-Rudloff \\
\hline Vice Chair: Vicky Schneider & Standardisation Committee \\
\hline Secretary: Michelle Brazas & Chair: Pascale Gaudet \\
\hline Treasurer: Fran Lewitter & Fund-raising Committee \\
\hline Learning, Education \& Training & Chair: Patricia Palagi \\
\hline Chair: Nicky Mulder & Technical Committee \\
\hline Co-Chair: Celia van Gelder & Chair: Manuel Corpas \\
\hline
\end{tabular}

\section{Defining GOBLET's priorities}

During the meeting, several break-out sessions were organised to help elucidate GOBLET's next steps and to inform its outreach strategy. From the discussions, publishing GOBLET's achievements to date and broadening GOBLET's horizons emerged as the most urgent priorities: amongst other things, GOBLET needs to position itself: I) to reach out effectively to all who need bioinformatics training, II) to attract individuals, small groups, students, as well as larger organisations, and III) to promote the importance of bioinformatics training to funding bodies, to grant holders and to universities.

To inform such activities, it was agreed that GOBLET should coordinate a survey (building on the survey conducted by SEB at the beginning of the year), aiming both to give a broader picture of training needs worldwide and to generate a
A common theme throughout the discussions was also continued development of the training portal. It was agreed that, above all, this resource needs to be non-redundant and to address real user needs. To this end, collaboration with other organisations will be essential, to identify synergies and to avoid costly duplication of effort - a particular priority for the Technical Committee is therefore to liaise with ELIXIR-UK in order to harmonise GOBLET's training portal with their plans to develop a Training e-Support Service (TeSS).

\section{Reaching out to the rest of the world}

It is important for GOBLET to reach out and attract new members for a variety of reasons: to expose new market-places for training; to open up potential new funding routes; to provide lobbying opportunities; to get recognition and buyin from established professions; and so on. In 


\section{Bioinformatics Training and Education: towards a sustainable global network \\ www.mygoblet.org}

The Global Organisation for Bioinformatics Learning, Education \& Training (GOBLET) evolved from the BTN - the Bioinformatics Training Network ${ }^{1}$. Arising from a recognised need to coordinate a spectrum of world-wide training activities in bioinformatics, biocuration, biocomputing and computational biology, its members aim to: share, not duplicate, effort; share, not duplicate, cost; to work together, in a mutually respectful way, towards common solutions and a sustainable future. Join us at www.mygoblet.org

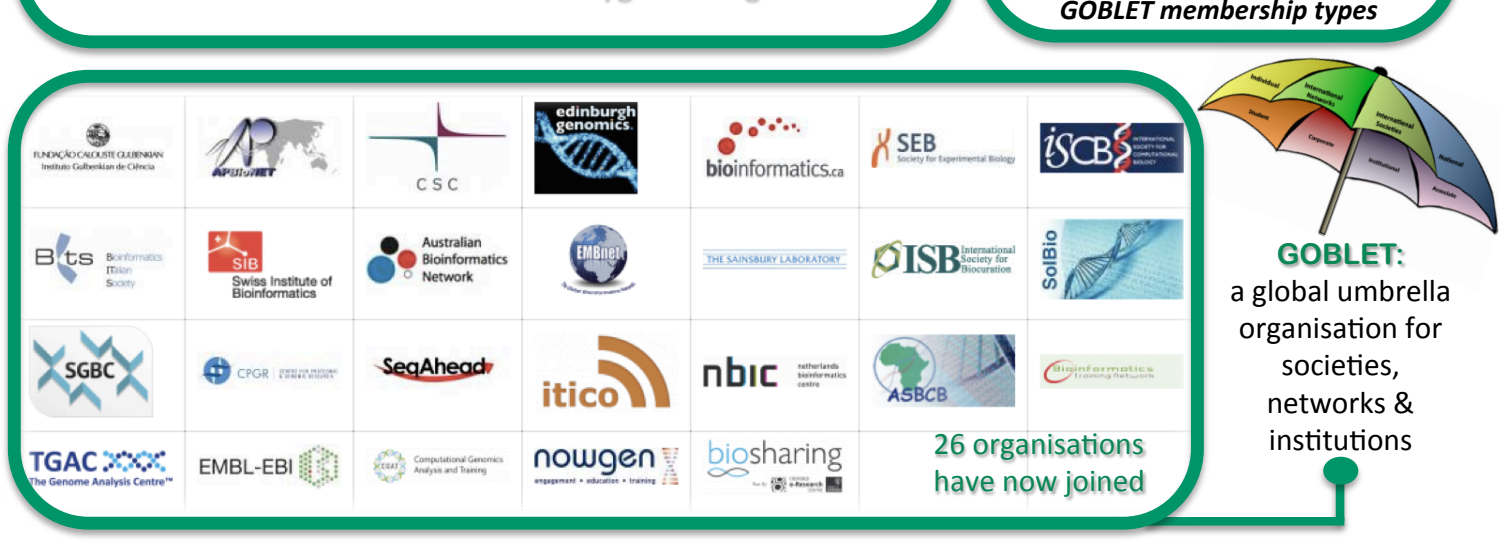

Steered by an Executive Board (elected by the membership) and five Committees (Education \& Training, Outreach \& PR, Technology, Standarisation and Fund-raising), GOBLET is about action working together towards pragmatic solutions to common problems ${ }^{2,3}$. Building on the work of the BTN, GOBLET has launched a Training Portal, offering a registry of trainers, organisers, events, and materials and documents, providing a sharing platform for trainers and trainees alike.

GOBLET worked with ISCB to establish a poster track for education at ISMB conferences. It is also developing standards for disseminating life science events ${ }^{4}$, preparing best practice guidelines for bioinformatics training 5 , exploring ways to bring recognition and accreditation to training, and is liaising with ELIXIR to interface with the European research infrastructure for biological data.

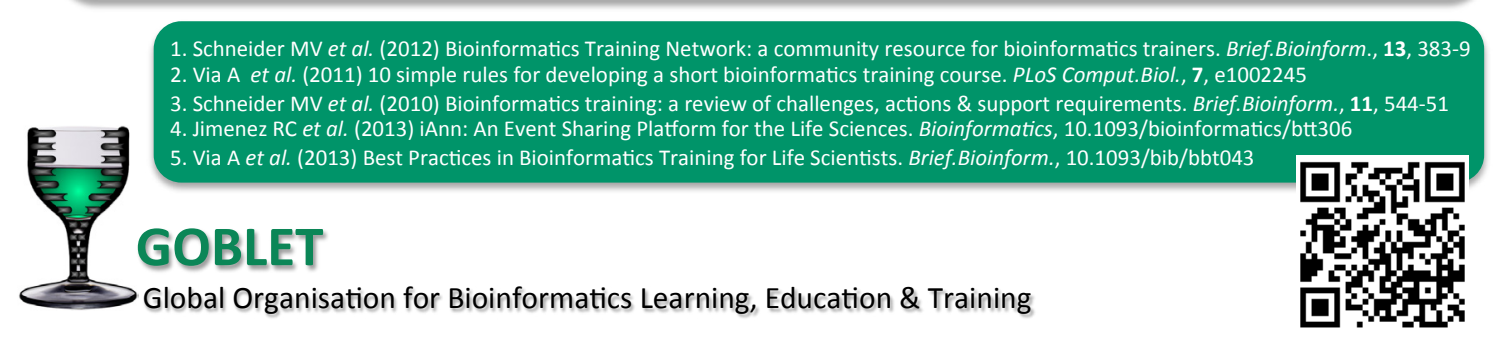

Figure 1. GOBLET's first poster, accepted in the new education track for ISMB2013 posters. 
return, reciprocal benefits for new members include, amongst many others, the formation of new collaborations, the chance to share best practices (Via et al., 2013) and, importantly, access to the trainers' registry, to a diverse array of bioinformatics training opportunities, and to a well-established bioinformatics trainer community. During the break-out discussions, numerous stake-holder groups were identified as potential targets for future outreach. Forging links with such groups will require the concerted efforts of GOBLET's new Executives and Committee Chairs; but all members can continue to play important roles as GOBLET ambassadors.

\section{Staying in touch}

Together, we've established the world's first global bioinformatics training organisation as a legal entity - GOBLET. The first AGM was an extremely positive and useful meeting, helping both to outline appropriate strategies to build on the foundations of the last year, and to elicit GOBLET's immediate priorities.

If you'd like to learn more about GOBLET, please visit the $\underline{\text { website }}^{5}$, or follow us on Twitter via@mygobletorg. To participate directly in our activities, a range of membership options ${ }^{6}$ is now available - we will be happy to welcome new members at any GOBLET events during the year, and especially at the next AGM, now scheduled to take place in Toronto, November 2014, hosted by bioinformatics.ca, with support from the recently awarded funds from the ClHR.

\section{References}

GOBLET Consortium. (2013) The Global Organisation for Bioinformatics Learning, Education \& Training (GOBLET). EMBnet.journal 19(1), 10-13. http://dx.doi.org/10.14806/ ej.19.1.606
Via A, Blicher T, Bongcam-Rudloff E, Brazas MD, Brooksbank $C$ et al. (2013) Best Practices in Bioinformatics Training for Life Scientists. Brief. Bioinform. 14(5), 528-537. http:!//dx.doi.: org/10.1093/bib/bbt043

\section{Consortium members}

Attwood, T.K. ${ }^{1}$, Blackford, S. ${ }^{2}$, Brazas, M.D. ${ }^{3}$, Brooksbank, C. ${ }^{4}$, Budd, A. ${ }^{5}$, Corpas, M. ${ }^{6}$, Davies, A. ${ }^{7}$, Fatumo, S. ${ }^{8}$, Fernandes, P.L. ${ }^{9}$, Gaudet, P.10, Hayer, J.1 ${ }^{11}$ Jimenez, R. ${ }^{4}$, Korpelainen, E.I.12, Kumithini, J.13, Maclean, D. ${ }^{14}$, McGrath, $A_{1}{ }^{15}$, Orengo, C.16, Palagi, P.M. ${ }^{10,17}$, Ponting, C. ${ }^{18}$, Sansone, S. ${ }^{19}$, Schneider, M.V. ${ }^{6}$, Schönbach, $C_{1}{ }^{20}$, Taylor, J.7, van Gelder, C.W.G. ${ }^{21,22}$, Vriend, G. ${ }^{22}$

1. Faculty of Life Sciences and School of Computational Biology, The University of Manchester, Manchester, UK; 2. The Society for Experimental Biology, Lancaster University, Lancaster, UK; 3. The Ontario Institute for Cancer Research, Ontario, Canada; 4. European Bioinformatics Institute, Hinxton, UK; 5. European Molecular Biology Laboratory, Heidelberg, Germany; 6. The Genome Analysis Centre, Norwich Research Park, Norwich, UK; 7. The Nowgen Centre, University of Manchester, UK; 8. Department of Computer and Information Sciences, Covenant University, Ota, Nigeria; 9. Instituto Gulbenkian de Ciência, Oeiras, Portugal; 10. University of Geneva, Geneva, Switzerland; 11. Department of Animal Breeding and Genetics, Swedish University of Agricultural Sciences, Uppsala, Sweden; 12. CSC - IT Center for Science, Espoo, Finland; 13. Centre for Proteomic and Genomic Research, Cape Town, South Africa; 14. The Sainsbury Laboratory, Norwich Research Park, Norwich, UK; 15. CSIRO Computational Informatics, Canberra, Australia; 16. Faculty of Life Sciences, University College London, London, UK; 17. SIB Swiss Institute of Bioinformatics, Switzerland; 18. Computational Genomics Analysis and Training, University of Oxford, Oxford, UK; 19. BioSharing, University of Oxford, Oxford, UK; 20. Department of Bioscience and Bioinformatics, Kyushu Institute of Technology, Fukuoka, Japan; 21. Netherlands Bioinformatics Centre, Nijmegen, The Netherlands; 22. Centre for Molecular and Biomolecular Informatics, Radboud University Nijmegen Medical Centre, Nijmegen, The Netherlands.

5 www.mygoblet.org

6 www.mygoblet.org/about-us/membership 